\title{
A Novel Bipolar Plate Design for Vanadium Redox Flow Battery Application
}

\author{
Linlin Yang ${ }^{1,2}$, Yu Zhou ${ }^{2}$, Shaopeng Wang ${ }^{2}$, Youbin Lin $^{2}$, Tao Huang ${ }^{1}$, Aishui Yu ${ }^{1, *}$ \\ ${ }^{1}$ Department of Chemistry, Collaborative Innovation Center of Chemistry for Energy Materials, \\ Shanghai Key Laboratory of Molecular Catalysis and Innovative Materials, Institute of New Energy, \\ Fudan University, Shanghai 200438, China \\ ${ }^{2}$ Shanghai Electric Group Co., Ltd. Central Academe, Shanghai 200070, China \\ "E-mail: asyu@ fudan.edu.cn
}

doi: $10.20964 / 2017.08 .71$

Received: 18 June 2016 / Accepted: 26 September 2016 / Published: 12 July 2017

\begin{abstract}
A novel design of bipolar plate (BP) was proposed for vanadium redox flow battery (VFB). The BP was prepared by injecting molten polyethylene into micropores of carbon fibers (CF) via molding method (simplified as MBP), which behaved high conductivity and great mechanical strength due to its special morphologies of conductive network structure uniform distribution made the fibers connecting with each other compared to the BP prepared by extrusion method (simplified as EBP). The electrochemical tests also showed the VFB with the composite MBP behaved better battery performance with higher voltage efficiency which could be attributed to the lower resistance of MBP consisting of conductive CF networks.
\end{abstract}

Keywords: Carbon materials; Electrical properties; Energy storage and conversion;

\section{$\underline{\text { FULL TEXT }}$}

(C) 2017 The Authors. Published by ESG (www.electrochemsci.org). This article is an open access article distributed under the terms and conditions of the Creative Commons Attribution license (http://creativecommons.org/licenses/by/4.0/). 